\title{
Analysis of trends in temperature and rainfall in selected regions of Australia over the last 100 years
}

\author{
G. Makuei $^{\mathrm{a}}$, L. McArthur ${ }^{\mathrm{a}}$ and Y. Kuleshov ${ }^{\mathrm{b}, \mathrm{a}}$ \\ ${ }^{a}$ School of Mathematical and Geospatial Sciences, RMIT University, Melbourne, Australia \\ ${ }^{b}$ National Climate Centre, Bureau of Meteorology, Melbourne, Australia \\ Email:s3097012@student.rmit.edu.au
}

\begin{abstract}
Climate change has a significant impact on the environment as well as the social, economic and political fabric of Australia. This paper examines historical trends in temperature and rainfall in regions of Australia which represent different climatic regimes.

In this study, we analyse trends in temperature and rainfall in three selected regions (Central eastern Queensland, south west Western Australia and central east Victoria) over the past 50-100 years. Observational data for daily maximum temperature, daily minimum temperature, daily mean temperature and total annual rainfall recorded at meteorological stations in these regions have been obtained from the National Climate Centre, Australian Bureau of Meteorology (BoM). Historical trends in the observational data have been examined using time series analysis. The results indicate that Australia is experiencing rapid climate change. Over the last 100 years, Australian temperatures have increased on average by approximately $1{ }^{\circ} \mathrm{C}$. Rainfall distribution across the continent has changed during the last century and even more pronounced changes in rainfall patterns are evident over recent decades. Since the 1950s, an increase in rainfall in the northwest of Australia has been observed. In contrast, significant decline in rainfall over eastern and southwestern Australia has been recorded. Consequently, such trend as well as changes in rainfall and temperature patterns have manifested in changes of frequency of climate extremes such as droughts and floods.

Detailed results of trend analysis of rainfall and temperature are presented. The results of this study are in good agreement with the findings of early studies.
\end{abstract}

Keywords: Climate change, temperature, rainfall 


\section{INTRODUCTION}

\subsection{Global Observations}

Crowley (2000) observed that $41-64 \%$ of the decade-scale temperature variations in pre-1850 were due to changes in solar irradiance and volcanic activities. However, greenhouse gas (GHG) effects accounted for most of the late $20^{\text {th }}$ century climate changes which are manifested in global temperature increases, sea level rise and widespread melting of Arctic sea ice and snow cover (IPCC 2007). This effect is likely to increase further in $21^{\text {st }}$ century. According to Hansen (2012), the current goal of limiting human-made warming to $2^{\circ} \mathrm{C}$ is insufficient to prevent climate-induced disasters. Solomon et al. (2009) pointed out that severity of damage due to climate change depends not only on magnitude, but on irreversibility also. The effect of GHG emissions is largely irreversible for hundreds of years after the emissions have stopped. Consequently, it is highly likely that significant increase in frequencies of climate extremes will be experienced for a long time, e.g. reduction of dry season rainfall and prolonged droughts in some regions, while other regions could experience excessive rainfall which will cause floods.

The Australian Government climate change adaptation framework was published in 2007 (Climate Change, 2007). Its goal is to reduce the risks of climate change impacts using all available opportunities. Climate change in Australia over a long period has been recognized and the needs for strategies of adaptation are also specified. The latest status report by the Australian Government (Climate Change Adaptation Framework) covers the period of 1910-2010/2011. Thus, a century-long analysis of historical trends in temperature and rainfall provides important scientific information for the government to make informed decisions on policies relating to climate change adaptation.

\subsection{Climate Change in Australia}

The Commonwealth Scientific and Industrial Research Organisation (CSIRO) and Australian Bureau of Meteorology (BoM) reported (CSIRO, 2012) that the annual average daily mean temperature of Australia has risen by $0.9^{\circ} \mathrm{C}$ since 1910 . It is projected to increase by $1-5^{\circ} \mathrm{C}$ by 2070 . Daily maximum and minimum temperatures also increased. A reduction in rainfall in Southwest Western Australian regions over long periods has been recorded. Seasonal patterns of rainfall also changed in different regions. These changes will likely to continue in the future leading to higher frequencies of climate extremes (floods and droughts).

Using a century-long homogenized daily temperature data set for Australia (Trewin, 2012), Wang et al. (2013) assessed changes in temperature extremes from 1910 to 2010. Twenty year return values of extreme low minimum temperature are found to have warmed strongly over the century in most parts of the continent. The observed changes in extreme temperatures are broadly consistent with observed changes in mean temperatures.

In this study, we present the analysis for three selected regions in Australia over the last 100 years to investigate long term historical trends in temperature and rainfall. Significant changes in both rainfall and temperature could potentially lead to changes in hydrological extremes such as floods and droughts, with high impact of Australian communities and country's economy.

\section{DATA AND METHODS}

\subsection{Data collection}

Observational data for daily maximum temperature, daily minimum temperature, daily mean temperature and total annual rainfall recorded at meteorological stations in these regions have been obtained from the National Climate Centre, Australian Bureau of Meteorology. Temperature and rainfall data were collected for the selected areas in Victoria, Queensland and Western Australia (Figure 1). Three or four weather stations in each region were selected for their high quality of long term meteorological records, and the measurements averaged for each region and each data set. The period of time for which temperature and rainfall data were available for the stations varied. For WA and VIC, the records span 106 years for all readings, but in QLD, only the rainfall was available for this length of time. The temperature data spanned 50 years, from $1962-$ 2012. 


\subsection{Data Analysis}

The data were divided into two groups; the first 53 years and second 53 years for all but the Queensland temperature data which were divided into two sets of 25 and 26 years respectively. Summary statistics including means and standard deviations were produced for temperature and rainfall observations. An independent sample t-test was conducted to investigate whether there are statistically significant differences in the mean temperature and rainfall measures for the periods 1907-1959 and 1960-2012 respectively, for WA and VIC, and 1962-1986 and 1987-2012 for QLD, Table 1.

\section{RESULTS}

\subsection{Temperature}

The temperature data for Victoria and Western Australia spans 1907 - 2012, and for Queensland, the temperature data spans 1962 - 2012. For this reason, Victorian and Western Australian data were divided into two sets of 53 samples, 1907 - 1959 and 1960 - 2012, and Queensland data two sets of samples $(\mathrm{n}=25$, 26 respectively) $1962-1986$ and $1987-2012$. The results indicate that annual mean minimum and annual mean temperature in Victoria and Western Australia have increased significantly between1960-2012 and in Queensland have increased significantly between1987-2012.

The results of the t-tests indicate that there are significant differences between the two periods for all measurements apart from annual mean maximum temperatures for Western Australia. These results concur with those of Wang et al. (2013) who found strong warming in extreme low minimum temperatures through most of Australia and a tendency towards warming for extreme high maximum temperatures, especially in south Western Australia and southern Victoria.

Table 1 shows that in all areas across all data sets (apart from annual mean maximum temperature in WA), the temperatures (minimum, mean and maximum) have increased over the past 50 years or so. An example of time series of annual mean minimum temperature for WA is presented in Figure 2 and clearly indicates statistically significant temperature increase since the 1950 s.

\subsection{Rainfall}

The results, Table 1, of the independent sample t-test for unequal variances indicate that the total annual rainfall for the period 1907-1959 in Western Australia is significantly different (greater) than the total annual rainfall for the period 1960-2012. These results suggest that total rainfall levels in WA have declined between 1907-1959 and 1960-2012 (Figure 3).

The changes in mean annual rainfall in the other regions indicated some general increase and decrease, but these changes were not statistically significant.

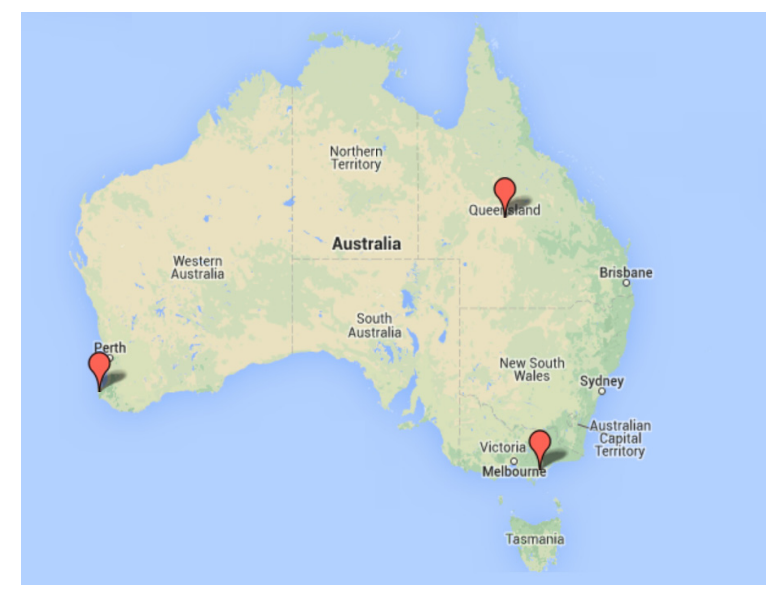

Figure1. Indicative locations of study sites in WA (Margaret River), VIC (Gippsland region) and QLD

(Longreach). 
Makuei et al. Climate change and the frequency of climate extremes in regions of Australia

Table1. Results of two sample t-test (two-tailed) for minimum, mean and maximum temperatures and total annual rainfall data. The variables are annual means, averaged over three or four stations in each region. The data were split into two groups: first 53 years and second 53 years, apart from the Queensland data whose temperature records only spanned $50^{+}$years.

\begin{tabular}{llcccccc} 
Region & \multicolumn{1}{c}{$\begin{array}{c}\text { Variable } \\
\text { (Annual Mean) }\end{array}$} & $n_{1,} n_{2}$ & $\mu_{1}$ & $\sigma_{1}$ & $\mu_{2}$ & $\sigma_{2}$ & $P$-value \\
\hline WA & Min. Temp $\left({ }^{\circ} \mathrm{C}\right)$ & 53,53 & 10.31 & 0.44 & 11.41 & 0.46 & $<0.001$ \\
& Mean Temp $\left({ }^{\circ} \mathrm{C}\right)$ & 53,53 & 15.91 & 0.05 & 16.12 & 0.49 & 0.003 \\
& Max Temp $\left({ }^{\circ} \mathrm{C}\right)$ & 53,53 & 21.44 & 0.42 & 21.45 & 0.61 & 0.920 \\
& Rainfall $(\mathrm{mm})$ & 53,53 & 917.97 & 141.89 & 834.49 & 140.42 & 0.003 \\
\multirow{2}{*}{ VIC } & Min Temp $\left({ }^{\circ} \mathrm{C}\right)$ & 53,53 & 9.87 & 0.36 & 11.19 & 0.54 & $<0.001$ \\
& Mean Temp $\left({ }^{\circ} \mathrm{C}\right)$ & 53,53 & 14.76 & 0.36 & 15.72 & 0.54 & $<0.001$ \\
& Max Temp $\left({ }^{\circ} \mathrm{C}\right)$ & 53,53 & 19.66 & 0.49 & 20.22 & 0.64 & $<0.001$ \\
& Rainfall $(\mathrm{mm})$ & 53,53 & 766.13 & 129.79 & 756.34 & 136.73 & 0.706 \\
\hline & Min Temp $\left({ }^{\circ} \mathrm{C}\right)$ & $25 *, 26$ & 15.86 & 0.75 & 16.22 & 0.67 & $<0.001$ \\
& Mean Temp $\left({ }^{\circ} \mathrm{C}\right)$ & 25,26 & 21.55 & 1.05 & 22.69 & 1.30 & 0.001 \\
& Max Temp $\left({ }^{\circ} \mathrm{C}\right)$ & 25,26 & 28.26 & 1.99 & 29.16 & 2.03 & 0.043
\end{tabular}

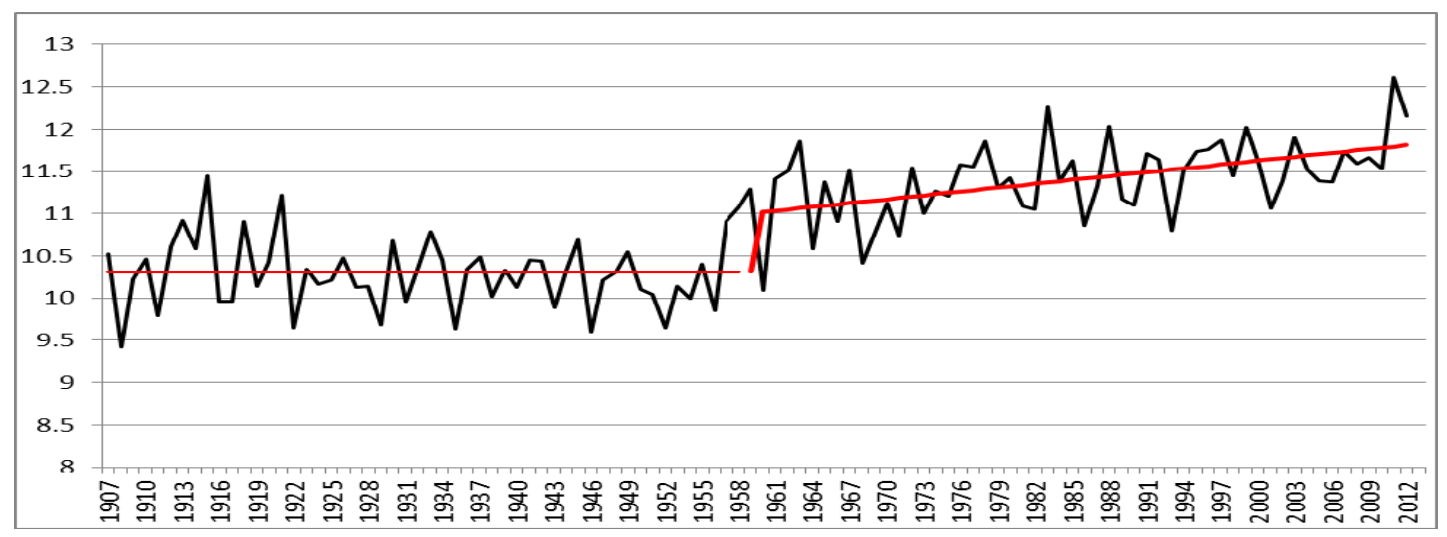

Figure 2. WA minimum temperature graph shows a significant increase in temperatures since the 1950s

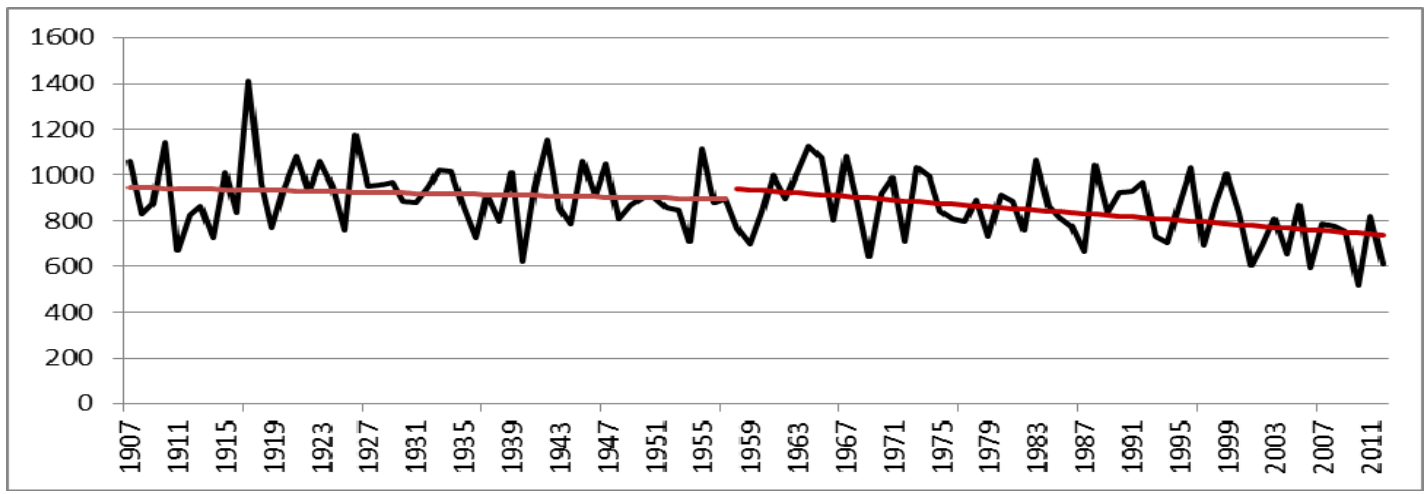

Figure 3. WA rainfall plot shows a significant decrease in rainfall since the 1950s 


\section{DISCUSSION}

This study investigates the changes in temperature and rainfall of three selected regions in Australia in two periods, 1907-1959 and 1960-2012. Mean annual minimum, maximum and average temperatures derived from daily records, and total annual precipitation records were estimated from meteorological observations archived at the National Climate Centre, BoM. The t-tests showed only decline in rainfall and increase in temperature in Western Australia to be significant. In spite of literature showing temperature rise, no such effect was noticeable in this study although trends were observed in some regions.

\section{CONCLUSION}

Among three Australian regions examined, the results showed significant differences between the two periods for both rainfall and temperature. There were only three sets whose difference was not significant: maximum temperature in WA, and rainfall in Victoria and Queensland. The results obtained in this study for temperature are consistent with those found in the literature. The results obtained in this study for rainfall are not as strong; this is partly due to the data being averaged over a year. There is evidence in the literature (Climate Change, 2007) that the rainfall patterns have changed, but this is shown more clearly by analysing the frequency of extreme events, such as longer dry periods and wetter wet periods. This is a topic for future study.

The changes in annual mean temperature between the two periods were found to be less than $1^{\circ} \mathrm{C}$. However, mean minimum temperature for Western Australia and for Queensland increased by $1.04^{\circ} \mathrm{C}$ and $1.01^{\circ} \mathrm{C}$, respectively. In the case of Victoria, the mean maximum temperature decreased by $1.25^{\circ} \mathrm{C}$. This illustrates again, the issue of increasing frequency of extreme events while maintaining a relatively stable mean. According to CSIRO (2012), mean annual temperature of Australia has risen by $0.9^{\circ} \mathrm{C}$ since 1910 . The period of observation in this study corresponds almost exactly to the period of CSIRO observations.

\section{REFERENCES}

Climate Change. (2007). National Climate Change Adaptation Framework. Australian Government.

Crowley, T. J. (2000). Causes of Climate Change Over the Past 1000 Years. Science, 289, 271-277.

CSIRO, B. (2012). State of Climate 2012. CSIRO and Bureau of Meteorology, Australia.

Hansen, J. E. (2012). Paleoclimate Implications for Human-Made Climate Change. In A. Berger, F. Mesinger, \& D. Sijacki (Eds.), Climate Change: Inferences from Paleoclimate and Regional Aspects (pp. 21-47). Springer Vienna.

IPCC. (2007). Climate Change 2007: The Physical Science Basis-Contribution of Working Group I to the Fourth Assessment Report of the Intergovernmental Panel on Climate Change-Summary for Policymakers. IPCC.

Solomon, S., Plattneb, G.-K., Knutti, R., and Friedlingstein, P. (2009). Irreversible climate change due to carbon dioxide emissions. PNAS, 106(6), 1704-1709.

Trewin, B. C. (2012). A daily homogenized temperature data set for Australia, Int. J. Climatol., published online 13 June 2012, doi:10.1002/joc.3530.

Wang, X.L., B. Trewin, Y. J. Feng, and D. Jones (2013) Historical changes in Australian temperature extremes as inferred from extreme value distribution analysis. Geophysical Research Letters. 40, 573-578. 